\title{
Paper
}

\section{A Correlation Analysis between the Number of Customers and Information Related to the Agriculture, Forestry, and Fisheries of Michi-no-eki in Japan}

\author{
TORU HiraOKA ${ }^{* \dagger}$ \\ Member, \\ SHIORI NisHIMURA ${ }^{\dagger}$ \\ HiROFumi NONAKA \\ Member, \\ TAKAO ITO ${ }^{\S}$ \\ Non-member \\ Minoru Kumano ${ }^{\mathbb{I}} \quad$ Non-member
}

(Received July 06, 2018, revised September 18, 2018)

\begin{abstract}
Michi-no-eki is one of the hot topics in Japan now. According to the Ministry of Land, Infrastructure, Transport, and Tourism, 1,134 Michi-no-eki have been registered as of November 2017. Agriculture, forestry, and fisheries is declining due to the rapidly decreasing birthrate and aging of the population. Michi-no-eki could be the key player in revitalizing the regional economy. Thus, to shed light on the relationship between Michi-no-eki and the agriculture, forestry, and fisheries, a correlation analysis between the number of Michi-no-eki customers and information associated with agriculture, forestry, and fisheries, such as the number of products sold out of retail facilities, the retail facilities area, and the number of farmers in each region of Japan, has been implemented. Information highly correlated with the number of customers in each region has been tested and the implication of the results are presented in this paper.
\end{abstract}

Keywords: Michi-no-eki, Correlation analysis, Number of customers, Agriculture, Forestry, Fishery

\section{Introduction}

In many regions of Japan, there has been a rapid decline in the population and aging of the society [1]. At the same time, there has been a notable decline in agriculture, forestry, and fisheries which are some of the main industries in Japan's regions [2]. It is inevitable that the regional economy will decline in kind; hence, there is a need for the regional economy to be reactivated through some means. Many organizations such as the Ministry of Land, Infrastructure, Transport and Tourism or local authorities are considering policies to realize regional revitalization by activating the regions using Michi-no-eki as the entry point as well as the base of a region [3] [4]. A Michi-no-eki is a facility that has three combined functions - a place for drivers to take a break, a place for information transmission for the local residents and drivers, and a place for regional cooperation to build vibrant local communities [5]. As of November 2017, there were 1,134 Michi-no-eki locations across Japan [6]. Regional collaborative functions at Michi-no-eki include collaborations with producers such as farmers and fishermen around the Michi-no-eki for the direct sales of agriculture, forestry, and fisheries products with the names and photos of the producers, as well as sales

\footnotetext{
* Corresponding author: hiraoka@sun.ac.jp

$\dagger$ Faculty of Information System, University of Nagasaki 1-1-1, Manabino, Nagayo-cho, Nishisonogi-gun, Nagasaki, Japan 851-2195

\$ Nagaoka University of Technology

$\S$ Hiroshima University

$\ddagger$ University of Miyazaki
}

of secondary products that have been processed from the agriculture, forestry, and fisheries primary products. Nowadays, the sales of regional agriculture, forestry, and fisheries products and processed goods have become a major speciality of the Michi-no-eki. Based on this, an improvement in the producers' income and the increase in the Michi-no-eki users can be expected.

In this document, we conduct an analysis of the relationship between the number of Michi-no-eki users and the agriculture, forestry, and fisheries related information in order to gain an understanding of how the sales of agriculture, forestry, and fisheries products and processed goods sales impact the number of users. Some customers stop at Michino-eki only to use the bathroom or to take a break. However, since it is difficult to precisely estimate the number of these users, we use the number of people going through the cash register counter as a proxy. Moreover, examples of agriculture, forestry, and fisheries related information in the Michi-no-eki are the number of direct sales of agriculture, forestry, and fisheries and produce store products as well as the facilities area and the number of farmers who supply agriculture, forestry, and fisheries products and are registered with the Michi-no-eki. We carry out a correlation analysis between the number of users and the agriculture, forestry, and fisheries related information to find out what information has the strongest correlation. The correlation analysis is applied to Michi-no-eki across the whole country. Furthermore, since the relationship between the number of users and the agriculture, forestry, and fisheries related 
Table 1: Number of Michi-no-eki analyzed in the experiment

\begin{tabular}{|c|c|c|c|c|c|c|c|c|c|}
\hline & $\begin{array}{l}\text { Number of } \\
\text { goods han- } \\
\text { dled (Total) }\end{array}$ & $\begin{array}{l}\text { Number } \\
\text { of goods } \\
\text { handled } \\
\text { (agri- } \\
\text { culture, } \\
\text { forestry, } \\
\text { and fish- } \\
\text { eries direct } \\
\text { sales store) }\end{array}$ & $\begin{array}{l}\text { Number } \\
\text { of locally } \\
\text { produced } \\
\text { goods } \\
\text { (agri- } \\
\text { culture, } \\
\text { forestry, } \\
\text { and fish- } \\
\text { eries direct } \\
\text { sales store) }\end{array}$ & $\begin{array}{l}\text { Number } \\
\text { of goods } \\
\text { handled } \\
\text { (produce } \\
\text { store) }\end{array}$ & $\begin{array}{l}\text { Number } \\
\text { of original } \\
\text { products } \\
\text { (produce } \\
\text { store) }\end{array}$ & $\begin{array}{l}\text { Facilities } \\
\text { area (Total) }\end{array}$ & $\begin{array}{l}\text { Facilities } \\
\text { area (agri- } \\
\text { culture, } \\
\text { forestry, } \\
\text { and fish- } \\
\text { eries direct } \\
\text { sales store) }\end{array}$ & $\begin{array}{l}\text { Facilities } \\
\text { area (pro- } \\
\text { duce store) }\end{array}$ & $\begin{array}{l}\text { Registered } \\
\text { supply } \\
\text { farmers }\end{array}$ \\
\hline $\begin{array}{l}\text { Whole } \\
\text { country }\end{array}$ & 653 & 661 & 661 & 667 & 688 & 736 & 716 & 715 & 712 \\
\hline Hokkaido & 59 & 58 & 58 & 64 & 64 & 69 & 69 & 69 & 60 \\
\hline Tohoku & 100 & 100 & 103 & 106 & 110 & 117 & 119 & 117 & 117 \\
\hline Kanto & 101 & 105 & 101 & 101 & 105 & 121 & 119 & 118 & 112 \\
\hline Hokuriku & 32 & 34 & 36 & 35 & 37 & 40 & 38 & 41 & 41 \\
\hline Chubu & 63 & 61 & 61 & 64 & 66 & 75 & 71 & 73 & 71 \\
\hline Kinki & 53 & 56 & 59 & 53 & 56 & 65 & 55 & 54 & 64 \\
\hline Chugoku & 84 & 83 & 82 & 83 & 83 & 80 & 75 & 76 & 80 \\
\hline Shikoku & 40 & 42 & 41 & 40 & 43 & 41 & 43 & 41 & 42 \\
\hline Kyushu & 116 & 117 & 116 & 116 & 118 & 122 & 121 & 119 & 121 \\
\hline Okinawa & 1 & 1 & 1 & 1 & 1 & 1 & 1 & 1 & 1 \\
\hline
\end{tabular}

information likely varies depending on the region, the correlation analysis is carried out a region-by-region basis as well (Hokkaido, Tohoku, Kanto, Hokuriku, Chubu, Kinki, Chugoku, Shikoku, Kyushu, Okinawa).

Previous studies have carried out correlation analyses related to Michi-no-eki in the Hokuriku region [7], the Kyushu region [8] [9], and some specific Michi-no-eki [10], but these studies did not consider Michi-no-eki across the whole country like this paper. Prior studies analyzing Michi-no-eki in the whole of Japan carried out correlation analysis with the number of cars parked at Michi-no-eki and the number of toilet seats [11]. This paper differs from previous research since it has carried out a correlation analysis between the number of Michi-no-eki users and the agriculture, forestry, and fisheries related information.

\section{The Number of Michi-no-eki Users and Agriculture, Forestry, and Fisheries Related Informationl}

The number of Michi-no-eki users and agriculture, forestry, and fisheries related information are measured for 2015 and a total of 1,107 Michi-no-eki across the country are analyzed. The number of Michi-no-eki in each region is: 117 in Hokkaido, 153 in Tohoku, 169 in Kanto, 78 in Hokuriku, 126 in Chubu, 141 in Kinki, 102 in Chugoku, 84 in Shikoku, 128 in Kyushu, and 8 in Okinawa.

The number of Michi-no-eki users is the number of people that pass through the cash register counter. Since many Michi-no-eki users stop only to use the bathroom or to rest, it is very difficult to accurately capture these types of users. Therefore, the numbers of people passing through the counter shall be used.

The agriculture, forestry, and fisheries related information includes 9 items - the number of goods handled via agriculture, forestry, and fisheries direct sales and produce stores [number], the number of goods handled through agriculture, forestry, and fisheries direct sales stores [number], the number of goods handled via agriculture, forestry, and fisheries direct sales stores which are locally produced [number], the number of goods handled at the produce stores [number], the number of goods handled that were originally at the produce stores [number], the forestry and fisheries direct sales and produce stores agriculture area $\left[\mathrm{m}^{2}\right]$, the agriculture, forestry, and fisheries direct sales facilities area $\left[\mathrm{m}^{2}\right]$, the produce stores facilities area $\left[\mathrm{m}^{2}\right]$, and the number of supply farmers registered with the Michi-noeki [number]. Hereinafter, the 9 items shall respectively be denoted as the number of goods handled (total), number of goods handled (agriculture, forestry, and fisheries direct sales store), number of locally produced goods (agriculture, forestry, and fisheries direct sales store), number of goods handled (produce store), number of original products (produce store), facilities area (total), facilities area (agriculture, forestry, and fisheries direct sales store), facilities area (pro-duce store), and the number of registered supply farmers. Agriculture, forestry, and fisheries direct sales stores sell products supplied by farmers or fishermen around the Michi-no-eki while produce stores sell souvenirs or special produce products. The facilities area is the floor area. The number of Michi-no-eki users in each region as well as the 9 data items are shown in Table 1. In the experiment below, we carry out correlation analysis. Okinawa was excluded from the scope of the experiment because we could obtain data for the 9 items from only one Michi-no-eki.

\section{Correlation Analysis}

A correlation analysis is carried out between the number of Michi-no-eki users and the agriculture, forestry, and fisheries related information. The correlation analysis was carried out for 90 combinations of the 9 agriculture, forestry, and fisheries related information items and the 9 regional categories, not including the whole country and the region of Okinawa.

Consider that there are Michi-no-eki in $M$ places and that 
Table 2: Correlation coefficients between the number of Michi-no-eki users and the agriculture, forestry, and fisheries related information.

\begin{tabular}{|c|c|c|c|c|c|c|c|c|c|}
\hline & $\begin{array}{l}\text { Number of } \\
\text { goods han- } \\
\text { dled (Total) }\end{array}$ & $\begin{array}{l}\text { Number } \\
\text { of goods } \\
\text { handled } \\
\text { (agri- } \\
\text { culture, } \\
\text { forestry, } \\
\text { and fish- } \\
\text { eries direct } \\
\text { sales store) }\end{array}$ & $\begin{array}{l}\text { Number } \\
\text { of locally } \\
\text { produced } \\
\text { goods } \\
\text { (agri- } \\
\text { culture, } \\
\text { forestry, } \\
\text { and fish- } \\
\text { eries direct } \\
\text { sales store) }\end{array}$ & $\begin{array}{l}\text { Number } \\
\text { of goods } \\
\text { handled } \\
\text { (produce } \\
\text { store) }\end{array}$ & $\begin{array}{l}\text { Number } \\
\text { of original } \\
\text { products } \\
\text { (produce } \\
\text { store) }\end{array}$ & $\begin{array}{l}\text { Facilities } \\
\text { area (Total) }\end{array}$ & $\begin{array}{l}\text { Facilities } \\
\text { area (agri- } \\
\text { culture, } \\
\text { forestry, } \\
\text { and fish- } \\
\text { eries direct } \\
\text { sales store) }\end{array}$ & $\begin{array}{l}\text { Facilities } \\
\text { area (pro- } \\
\text { duce store) }\end{array}$ & $\begin{array}{l}\text { Registered } \\
\text { supply } \\
\text { farmers }\end{array}$ \\
\hline $\begin{array}{l}\text { Whole } \\
\text { country }\end{array}$ & 0.052 & 0.056 & 0.035 & 0.048 & 0.017 & $0.332 * *$ & $0.297 * *$ & $0.226 * *$ & $0.326^{* *} *$ \\
\hline Hokkaido & $0.456^{* * *}$ & 0.650 ** & $0.351 * *$ & 0.168 & $0.299^{*}$ & 0.459 & $0.511 * *$ & $0.236 * *$ & $0.305^{*}$ \\
\hline Tohoku & 0.165 & 0.095 & 0.083 & $0.232^{*}$ & -0.029 & $0.329 * *$ & $0.391 * *$ & $0.229 *$ & $0.369 * *$ \\
\hline Kanto & 0.132 & 0.074 & 0.080 & $0.206^{*}$ & 0.059 & $0.219^{*}$ & $0.216^{*}$ & $0.214 *$ & $0.261 * *$ \\
\hline Hokuriku & $0.475^{* *} *$ & $0.530 * *$ & $0.499 * *$ & 0.233 & 0.202 & $0.665 * *$ & $0.659 * *$ & $0.307 * *$ & $0.272^{*}$ \\
\hline Chubu & $0.914 * *$ & $0.674 * *$ & $0.613 * *$ & $0.899 * *$ & -0.009 & $0.395 * *$ & 0.222 & $0.265^{*}$ & 0.001 \\
\hline Kinki & 0.187 & $0.481 * *$ & 0.222 & 0.008 & 0.248 & $0.558 * *$ & $0.452 * *$ & $0.419 * *$ & $0.714 * *$ \\
\hline Chugoku & 0.129 & 0.166 & 0.097 & 0.100 & 0.099 & $0.521 * *$ & $0.452 * *$ & $0.455^{* *}$ & 0.215 \\
\hline Shikoku & $0.547 * *$ & $0.457 * *$ & $0.655 * *$ & $0.453 * *$ & 0.145 & $0.555^{*} *$ & $0.701 * *$ & 0.277 & $0.488 * *$ \\
\hline Kyushu & $0.228 *$ & $0.267 * *$ & $0.281 * *$ & 0.141 & $0.321 * *$ & $0.460 * *$ & $0.472 * *$ & 0.075 & $0.559 * *$ \\
\hline
\end{tabular}

※*: $1 \%$ significance level; *: $5 \%$ significance level; no *: $10 \%$ significance level; gray background: higher than $10 \%$ significance level

$P_{m}$ people use the $m(=1,2, \cdots, M)$ th Michi-no-eki. Moreover, consider that the $n(=1,2, \cdots, 9)$ th item of the 9 agriculture, forestry, and fisheries related information items is $Q_{m, n}$. The correlation coefficient $C_{n}$ between the number of Michi-no-eki users $P_{m}$ and the $n$th data in the agriculture, forestry, and fisheries related information, $Q_{m, n}$, can be calculated using the following equation.

$$
\begin{aligned}
& C_{n}=\frac{\sum_{m=0}^{M}\left(P_{m}-\bar{P}\right)\left(Q_{m, n}-\overline{Q_{n}}\right)}{\sqrt{\sum_{m=1}^{M}\left(P_{m}-\bar{P}\right)^{2} \sum_{m=1}^{M}\left(Q_{m, n}-\overline{Q_{n}}\right)^{2}}} \\
& \bar{P}=\frac{\sum_{m=1}^{M} P_{m}}{M} \\
& \overline{Q_{n}}=\frac{\sum_{m=1}^{M} Q_{m, n}}{M}
\end{aligned}
$$

We carried out a $t$-test to check whether there is a correlation between the number of Michi-no-eki users and $n$th data item from the agriculture, forestry, and fisheries related information. The null hypothesis is that there is no correlation between the number of Michi-no-eki users and the $n$th data item from the agriculture, forestry, and fisheries related information. A significance level $\alpha$ is set and the value $k_{a, n}$ is obtained from the $t$-distribution. The test statistic $T_{n}$ is obtained from the following equation:

$$
T_{n}=\frac{C_{n} \sqrt{M-2}}{\sqrt{1-C_{n}^{2}}}
$$

The null hypothesis is rejected when $T_{n}>k_{\alpha, n}$ and, in this case, there is evidence about the existence of correlation between the number of Michi-no-eki users and th data item from the agriculture, forestry, and fisheries related information given the chosen significance level $\alpha$.

\section{Experiment and Results}

We carried out a correlation analysis between the Michino-eki across the whole country and in each region and the agriculture, forestry, and fisheries related information. The results are shown in Table 2 . In Table 2, if the correlation coefficient between the number of Michi-no-eki users and the agriculture, forestry, and fisheries related information is significant at the $1 \%$ or $5 \%$ significance level, it is marked with $* *$ and $*$ on the side, respectively. No mark is placed if the coefficient is significant at the $10 \%$ significance level. If the significance level is greater than $10 \%$, the background color of the correlation coefficient is gray. Hereinafter, if the absolute value of the correlation coefficient is between 0.7 and 1.0, it shall be described as "having a strong correlation", if the correlation coefficient is between 0.7 and 0.4 , as "having a correlation", if the correlation coefficient is between 0.4 and 0.2 , as "having a week correlation", and as ' having no correlation' if it is between 0.2 and 0 .

As the correlation analysis for the whole country shows, there were weak correlations with the facilities area (total), the facilities area (agriculture, forestry, and fisheries direct sales store), the facilities area (produce store), and the number of registered supply farmers. Moreover, there was no correlation with the number of goods handled (total), the number of goods handled (agriculture, forestry, and 
fisheries direct sales store), the number of locally produced goods (agriculture, forestry, and fisheries direct sales store), the number of goods handled (produce store), and the number of original products (produce store). In other words, in order to increase the number of Michi-no-eki users across the entire country, it is important to broaden the agriculture, forestry, and fisheries direct sales or produce store facilities and increase the number of farmers rather than increase the number of agriculture, forestry, and fisheries products handled at Michi-no-eki.

The result of correlation analysis for Hokkaido showed that there were correlations with the number of goods handled (total), the number of goods handled (agriculture, forestry, and fisheries direct sales store), the facilities area (total), and the facilities area (agriculture, forestry, and fisheries direct sales store). Moreover there were weak correlations with the number of locally produced goods (agriculture, forestry, and fisheries direct sales store), the number of original products (produce store), the facilities area (produce store), and the number of registered supply farmers. In other words, in order to increase the number of Michino-eki users in Hokkaido, it is better to increase the number of products handled through agriculture, forestry, and fisheries direct sales stores rather than the produce stores, and broaden the facilities area.

The correlation analysis for the Tohoku region showed that there were weak correlations with the number of goods handled (produce store), the facilities area (total), the facilities area (agriculture, forestry, and fisheries direct sales store), the facilities area (produce store), and the number of registered supply farmers. In other words, to increase the number of Michi-no-eki users in the Tohoku region, it is better to broaden the facilities for direct sales stores of agriculture, forestry, and fisheries as well as produce stores and increase the number of farmers that will supply agriculture, forestry, and fisheries products.

The correlation analysis in the Kanto region showed that there were weak correlations with the number of goods handled (produce store), the facilities area (total), the facilities area (agriculture, forestry, and fisheries direct sales store), and the facilities area (produce store). The number of registered supply farmers had a low correlation coefficient of just above 0.2 . In other words, it will be challenging to increase the number of Michi-no-eki users in the Kanto region even if the number of agriculture, forestry or fishery products handled is increased and the facilities areas are broadened.

The correlation analysis for the Hokuriku region showed that there were correlations with the number of goods handled (total), the number of goods handled (agriculture, forestry, and fisheries direct sales store), the number of locally produced goods (agriculture, forestry, and fisheries direct sales store), the facilities area (total), and the facilities area (agriculture, forestry, and fisheries direct sales store). Among these, the correlation coefficients for the facilities area (total) and for the facilities area (agriculture, forestry, and fisheries direct sales store) were relatively large, 0.665 and 0.659 , respectively. Moreover, there were weak correla- tions with the facilities area (produce store) and the number of registered supply farmers. In other words, to increase the number of Michi-no-eki users in the Hokuriku region, broadening of the agriculture, forestry, and fisheries direct sales facilities area will have a significant effect. Moreover, increasing the number of goods and local products of the agriculture, forestry, and fisheries handled through direct sales may also have an effect.

The correlation analysis for the Chubu region showed that the correlation coefficients with the number of goods handled (total) and the number of goods handled (produce store) are 0.914 and 0.889 , respectively, showing strong correlations. Moreover, the correlation coefficients with the number of goods handled (agriculture, forestry, and fisheries direct sales store) and the number of locally produced goods (produce store) were 0.674 and 0.613 , respectively, showing a correlation. There were also weak correlations with the facilities area (total), the facilities area (agriculture, forestry, and fisheries direct sales store), and the facilities area (produce store). In other words, to increase the number of Michi-no-eki users in the Chubu region, increasing the number of goods handled at produce stores would have a significant effect. Increasing the number of goods handled through agriculture, forestry, and fisheries direct sales store or the number of agriculture, forestry, and fisheries products produced locally would also result in relatively positive outcome.

As a result of correlation analysis for the Kansai region, the correlation coefficient for the number of registered supply farmers was 0.714 , showing a strong correlation. Moreover, there were correlations with the number of goods handled (agriculture, forestry, and fisheries direct sales store), the facilities area (total), the facilities area (agriculture, forestry, and fisheries direct sales store), and the facilities area (produce store). There were weak correlations with the number of locally produced goods (agriculture, forestry, and fisheries direct sales store) and the number of original products (produce store). In other words, to increase the number of Michi-no-eki users in the Kansai region, increasing the number of farmers supplying agriculture, forestry, and fisheries products would result in a very strong effect. Moreover, increasing the number of goods handled through direct sales of agriculture, forestry, and fisheries products and expanding the facilities area would also result in a positive outcome.

The correlation analysis for the Chugoku region showed that there were correlations with the facilities area (total), the facilities area (agriculture, forestry, and fisheries direct sales store), and the facilities area (produce store). Moreover, there was a weak correlation with the number of registered supply farmers. In other words, to increase the number of Michi-no-eki users in the Chugoku region, the facilities area should be expanded.

The correlation analysis for the Shikoku region showed that there was a strong correlation with the facilities area (agriculture, forestry, and fisheries direct sales store), with a correlation coefficient of 0.701 . Moreover, there were correlations with the number of goods handled (total), the num- 
ber of goods handled (agriculture, forestry, and fisheries direct sales store), the number of locally produced goods (agriculture, forestry, and fisheries direct sales store), the number of goods handled (produce store), the facilities area (total), and the number of registered supply farmers. Even among these, the number of locally produced goods (agriculture, forestry, and fisheries direct sales store) had a relatively high correlation coefficient of 0.655 . Furthermore, there was a weak correlation with the facilities area (produce store). In other words, in order to increase the number of Michi-no-eki users in the Shikoku area, widening the facilities area for agriculture, forestry, and fisheries direct sales would be extremely effective. Moreover, a good result can be expected if the number of agriculture, forestry, and fisheries locally produced goods is increased as well. Furthermore, increasing the number of farmers supplying agriculture, forestry, and fisheries goods and the number of goods handled is also expected to have an effect.

The correlation analysis for the Kyushu region showed that there were correlations with the facilities area (total), the facilities area (agriculture, forestry, and fisheries direct sales store), and the number of registered supply farmers. Moreover, there were weak correlations with the number of goods handled (total), the number of goods handled (agriculture, forestry, and fisheries direct sales store), the number of locally produced goods (agriculture, forestry, and fisheries direct sales store), and the number of original products (produce store). In other words, to increase the number of Michi-no-eki users in the Kyushu region, increasing the number of farmers who supply agriculture, forestry, and fisheries products and broadening the facilities area for agriculture, forestry, and fisheries direct sales will be effective.

The agriculture, forestry, and fisheries related information items which exhibited a high correlation with the number of Michi-no-eki users varied depending on the region. In other words, to increase the number of Michi-no-eki users, measures appropriate for each region are required. Overall, it became apparent that the correlation coefficients between the agriculture, forestry, and fisheries related information and the facilities area were bigger and the correlations tended to be higher for information related to agriculture, forestry, and fisheries direct sales store relative to produce stores. Moreover, it became apparent that the correlation coefficient with the number of registered supply farmers increased and there was a big difference in the correlation coefficients for the number of locally produced goods (agriculture, forestry, and fisheries product stores) between the regions. Moreover, there was hardly any correlation with the number of original products (produce store).

\section{Conclusion}

To understand what impact the agriculture, forestry, and fisheries products and processed items sales via Michino-eki have on the number of users, the relationship between the number of Michi-no-eki users and the agriculture, forestry, and fisheries related information was analyzed. In this paper, we used correlation analysis to establish which agriculture, forestry, and fisheries related information items have a high correlation with the number of Michi-no-eki users. The correlation analysis showed that the agriculture, forestry, and fisheries related information items that had a high correlation with the Michi-no-eki users varied depending on the region. Overall, in order to increase the number of Michi-no-eki users, it is better to expand the facilities area than to increase the number of goods handled, it is better to put more effort into direct sales of agriculture, forestry, and fisheries than into produce stores, and it is better to increase the number of farmers supplying agriculture, forestry, and fisheries products registered with the Michino-eki.

Finally, we hope that a presentation of these research results to self-governing bodies across the country will lead to an increase in the number of Michi-no-eki users.

\section{Acknowledgements}

This research has been made possible with great help from the Kyushu-Okinawa Michi-no-eki Network with respect to carrying out a survey of customers passing through the cash register counters, etc. Moreover, this study was carried out with help from 2017 research from JACIC (Japan Construction Information Center Foundation). We are sincerely grateful.

\section{References}

[1] Statistics Bureau, Ministry of Internal Affairs and Communications, Estimate of the Population, http://www. stat. go.jp/data/jinsui/index.html, 2018.

[2] Ministry of Agriculture, Forestry and Fisheries, Annual Report on Food, Agriculture and Farm Vil-lage, Annual Report on Forest and Forestry, An-nual Report on Marine Product, http://www.maff.go.jp/j/wpaper/, 2017.

[3] Road Bureau, "Ministry of Land, Infrastructure, Transport and Tourism", The Formation of Regional Revitalization Bases via "Michi-no-eki", http://www.mlit.go.jp/ common/001052858.pdf, 2014.

[4] S. Akiyama, "Michi-no-eki" Activation of Regions by Roadside Stations, JICE Report, vol.27, pp.6-50, 2015.

[5] Ministry of Land, Infrastructure, Transport and Tour-ism, Roadside Station Information, http://www.mlit.go.jp/ road/Michi-no-Eki/, 2018.

[6] National Roadside Station Liaison Conference, Official Homepage of Roadside Station, https: //www . michi-noeki.jp/, 2018.

[7] Y. Sakuma, K. Sano, S. Tsuchiya and M. Kawabata, "A Study on the Users' Satisfaction of Road Stations in Hokuriku Region", Infrastructure Planning and Management - Collection of Lectures, vol.42, 168, pp.1-6, 2010.

[8] T. Hiraoka, H. Nonaka and M. Kumano, "Analysis of Stopby Rate to Mitinoeki in Region in the Case of Kyushu", Journal of the Japan Society of Photogrammetry and Remote Sensing, vol.56, no.4, pp.133-136, 2017. 
[9] T. Hiraoka, H. Nonaka, T. Ito and M. Kumano, "A Correlation Analysis between Land Use and Number of Customers of Michi-no-eki in Kyusyu Region”, Journal of the Japan Society of Photogrammetry and Remote Sensing, vol.57, no.1, pp.29-33, 2018.

[10] E. Minato, N. Ise, and S. Sakurai, "Roadside Stations are Expected as Bases of Vitalizing Local Economy", Journal for Regional Policy Studies, vol.9, pp.35-47, 2017.

[11] M. Kumano, "Michi-no-eki in All of Japan - the Direction of Regional Promotion of Self-governing Bodies through the Advancement of Roadside Stations", The 35th Regional Self-governing Bodies Research - All Japan Meeting, Local Autonomy/Government Study Whole Country Meeting, http://www.jichiro.gr.jp/jichiken_kako/ report/rep_saga35/05/0521_ron/index.html, 2014.

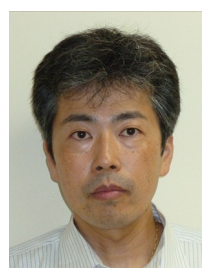

Toru Hiraoka (Member) received B.Des., M.Des. and D.Eng. degrees from Kyushu Institute of Design in 1995, 1997 and 2005, respectively. He is currently a Professor in University of Nagasaki. His research interests include non-photorealistic rendering and disaster prevention.

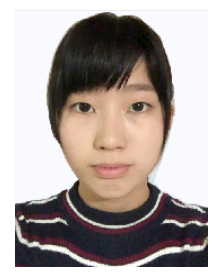

Shiori Nishimura (Non-member) is currently a student in University of Nagasaki. Her research interests include machine learning and regional activation.

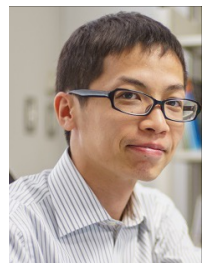

Hirohumi Nonaka (Member) received B.Eng., M.Eng. and D.Eng. degrees from Toyohashi University of Technology in 2003, 2005 and 2011, respectively. He is currently a Associate Professor in Nagaoka University of Technology. His research interests include data-mining and text-mining.

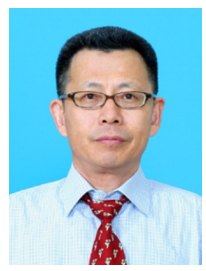

Takao Ito (Non-member) is Professor of Management of Technology (MOT) in Graduate School of Engineering at Hiroshima University. His current research interests include automaton theory, the MOT and quantitative analysis of Michi-no-Eki using mathematical models.

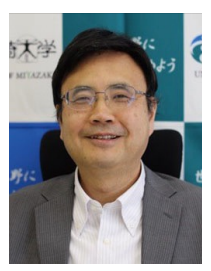

Minoru Kumano (Non-member) received B.Eng. from Toyohashi University of Technology in 1981, and D.Eng. degrees from Nagaoka University of Technology in 2002. He is currently a Professor of Faculty of Regional Innovation at University of Miyazaki in Japan. His research interests include Michi-no-Eki, regional planning and disaster prevention. 